\title{
Análise das concessões de lavra quanto às suspensões temporárias de operação
}

\author{
(Analysis of the mining rights related to \\ temporary suspensions of mining)
}

\section{Resumo}

O presente artigo relata os resultados da análise das concessões de lavra no Estado de Minas Gerais. O objetivo desse estudo foi analisar as concessões de lavra outorgadas no Estado, tendo como metodologia a classificação dos processos existentes no Cadastro Mineiro em: minas ativas, minas com suspensão de lavra protocolizada no DNPM (Departamento Nacional de Produção Mineral) e minas com suspensão publicada no DOU (Diário Oficial da União). Atualmente, das 1.739 concessões de lavra no Estado, 234 minas encontram-se com suspensão temporária de lavra. Esse estudo apresenta os resultados da análise desenvolvida e enfatiza a ausência e a premência da estruturação e implantação de uma política de fechamento de minas e de controle rígido de minas com suspensão temporária, bem como das abandonadas.

Palavras-chave: Concessão de lavra, suspensão temporária de lavra, minas.

\section{Alessandro Gomes Resende \\ Engenheiro de Minas Mestrando em Engenharia Mineral pelo PPGEM / EM / UFOP \\ E-mail: alessandrogr@hotmail.com}

\section{Hernani Mota de Lima}

Professor, Departamento de Engenharia de Minas/EM/UFOP E-mail: hernani.lima@ufop.br

\section{Abstract}

This paper reports the results of analysis of exploitation consents in the Minas Gerais State. The objective this study was map the exploitation consents granted in the State, in order to classify the existing processes in the Mining Cadastre in: active mines, mines with suspension of extraction registered in the National Department of Mineral Production and mines with suspension of extraction published in the Official Gazette. The results showed that there 1.739 consents in the State, where the mines with temporary suspension of extraction added 234 mines. This work presents the results of this analysis and highlights the absence and the need of the development and implementation of a mine closure policy and control and enforcement on dealing with mines on temporary suspension status as well as abandoned ones.

Keywords: Mining rights, temporary suspension of mining, mines. 


\section{Introdução}

Segundo o Código de Mineração, os titulares de concessões de lavra no Brasil podem obter a suspensão temporária da lavra, mediante requerimento justificado ao Diretor-Geral do DNPM. Um relatório dos trabalhos efetuados e do estado geral da mina e suas possibilidades futuras devem acompanhar tal requerimento. Entretanto, mesmo quando a suspensão, ou fechamento, é apenas temporário, em virtude de circunstâncias inesperadas, ele é preocupante, pois não se sabe qual será o tempo sem operação e quais as implicações ambientais e de segurança das instalações (por ex. mina, pilhas e barragens) dessa paralisação. Efeitos do clima, bem como os antrópicos, podem maximizar alguns problemas relativos às minas fechadas temporariamente, tais como: segurança e saúde de populações adjacentes, evolução dos processos erosivos, assoreamento dos cursos d'água e o aumento de áreas contaminadas (Camelo, 2006). Um programa de monitoramento e manutenção deveria ser apresentado e posto em prática de forma a garantir a segurança, a minimização dos impactos e a retomada das operações, assim que as condições que causaram a sua suspensão temporária deixarem de existir.

Com o objetivo de analisar a situação das concessões outorgadas no Estado de Minas Gerais, foram estudados os processos existentes no cadastro mineiro, de forma a constituir um mapeamento das concessões de lavra, bem como subdividir os processos existentes em: minas ativas, minas com suspensão de lavra protocolizada no DNPM e minas com suspensão de lavra publicada no DOU. Os aspectos que nortearam a realização dessa pesquisa incluem:

1. Falta de conhecimento sobre a situação operacional das concessões de lavra existentes no Estado de Minas Gerais.

2. Ausência de cadastro das minas com lavra ativa e com suspensão temporária de lavra nos órgãos e agências governamentais.
3. Ausência de cadastro das minas com suspensão temporária de lavra publicadas e protocolizadas.

4. Ausência de cadastro de áreas degradadas pela mineração.

5. Necessidade de elaboração de um banco de dados sobre minas abandonadas e fechadas, em definitivo ou temporariamente, para a proposição de um programa governamental sobre o fechamento de mina.

\section{Metodologia}

Essa pesquisa foi elaborada tendo como base os estudos de Lima (2007), o qual chama a atenção para a situação de minas abandonadas, fechadas e em suspensão temporária. Para a elaboração do estudo, foi feito, inicialmente, o levantamento dos números dos processos de todas as concessões de lavra outorgadas no Estado, de forma a permitir consultar a situação de cada um deles no Cadastro Mineiro, disponível no site do DNPM (http://dnpm.gov.br), onde estão disponíveis os dados básicos de cada processo, incluindo títulos, substâncias, municípios, condições de propriedade do solo, representação gráfica da poligonal, entre outras informações. Posteriormente, a partir dos dados básicos, foram analisados, em detalhe, os processos de todas as concessões de lavra outorgadas no Estado de Minas Gerais. Com o mapeamento realizado, foi apresentada a síntese dos principais resultados e análises, tendo por base a regulamentação existente, tanto em nível de DNPM, quanto da Fundação Estadual do Meio Ambiente (FEAM).

\section{Resultados}

\subsection{Análise dos dados disponíveis no Cadastro Mineiro}

Existem, atualmente, 1.739 concessões de lavra no Estado de Minas Gerais, sendo que as minas com suspen- são temporária de lavra protocolizadas no DNPM são 145 e as minas com suspensão temporária de lavra, publicadas no DOU, somam 89 minas. As concessões com suspensão temporária totalizam 234 minas, o que representa $13,46 \%$ das concessões de lavra outorgadas no Estado. As minas, efetivamente, em lavra atingem 1.505 minas. Cabe ressaltar, entretanto, que, além das minas oficiais, existem várias outras não regularizadas, incluindo, aqui, os garimpos de ouro, e de diamante e demais pedras preciosas e "extrações" clandestinas de agregados para construção civil. Essa clandestinidade se deve à excessiva burocracia dos processos de legalização, à descontinuidade da exploração, à falta de fiscalização e à dificuldade com os custos de regulamentação desse tipo específico de empreendimento minerário (Viana, 2007).

A avaliação das concessões de lavra possibilitou verificar que, no caso das minas com suspensão protocolizada no DNPM, 43\% das mineradoras são consideradas de pequeno porte e $35 \%$ de grande porte. Em relação às minas com suspensão publicada no DOU, as minas de pequeno porte totalizam $56 \% \mathrm{e}$ as de grande porte, $37 \%$.

As figuras apresentadas a seguir explicitam os resultados de nossa pesquisa, os quais foram obtidos a partir de dados disponíveis no site do DNPM. A Figura 1 apresenta todas as concessões de lavra outorgadas atualmente em Minas Gerais, mostrando como destaques a maior concentração das concessões na região central do Estado, motivadas principalmente pelo minério de ferro do Quadrilátero Ferrífero e, também, na região de Poços de Caldas e Cataguases (bauxita), Bocaiúva (quartzo) e Triângulo Mineiro (fosfato).

A Figura 2 apresenta a localização georeferenciada das concessões de lavra no Estado de Minas Gerais, de acordo com a sua classificação em: minas com suspensão protocolizada, minas com suspensão publicada e áreas teoricamente em lavra. A Figura 3 apresenta o mapeamento das concessões de lavra no Estado em relação à substância mineral explotada. 


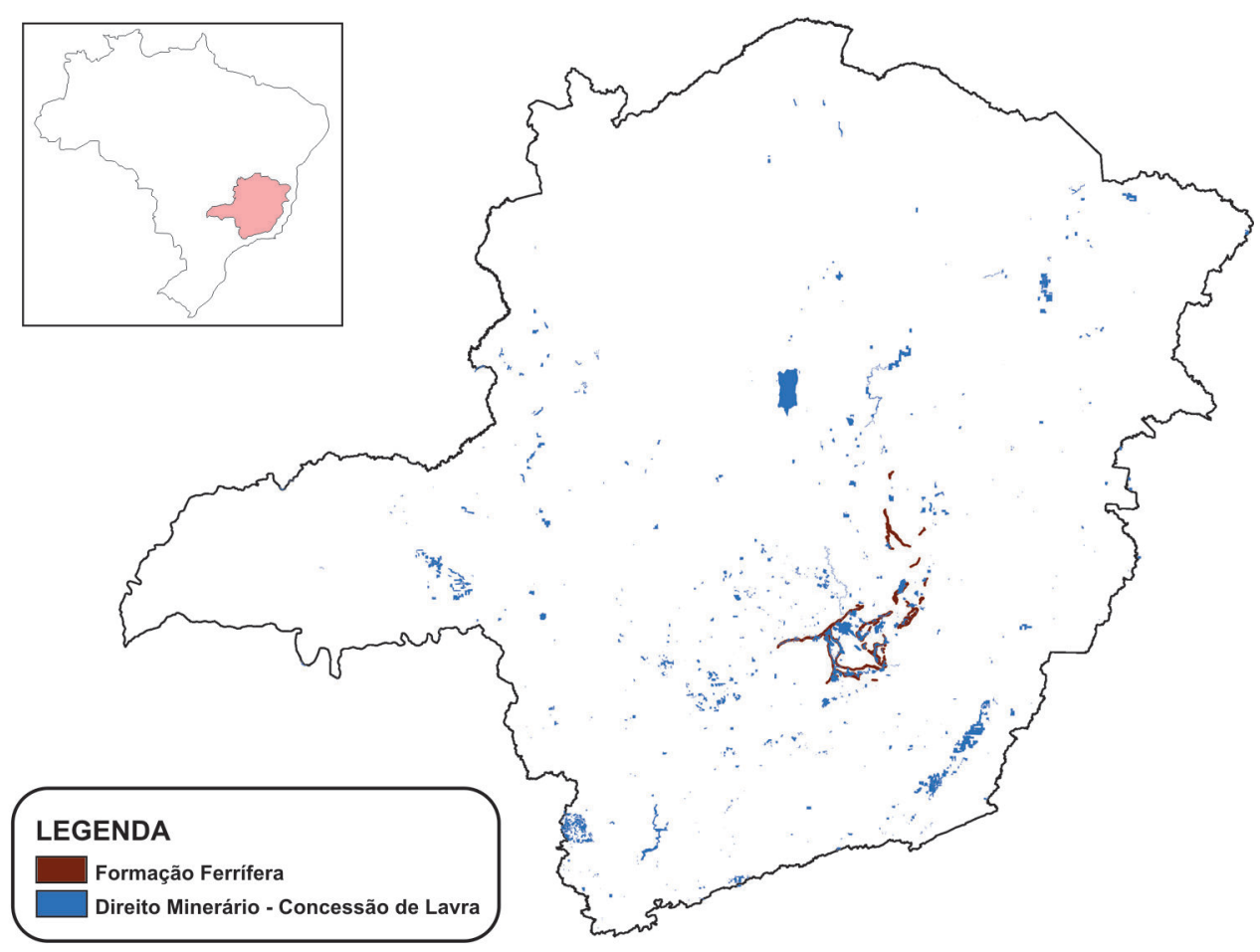

Figura 1 - Concessões de lavra no Estado de Minas Gerais.

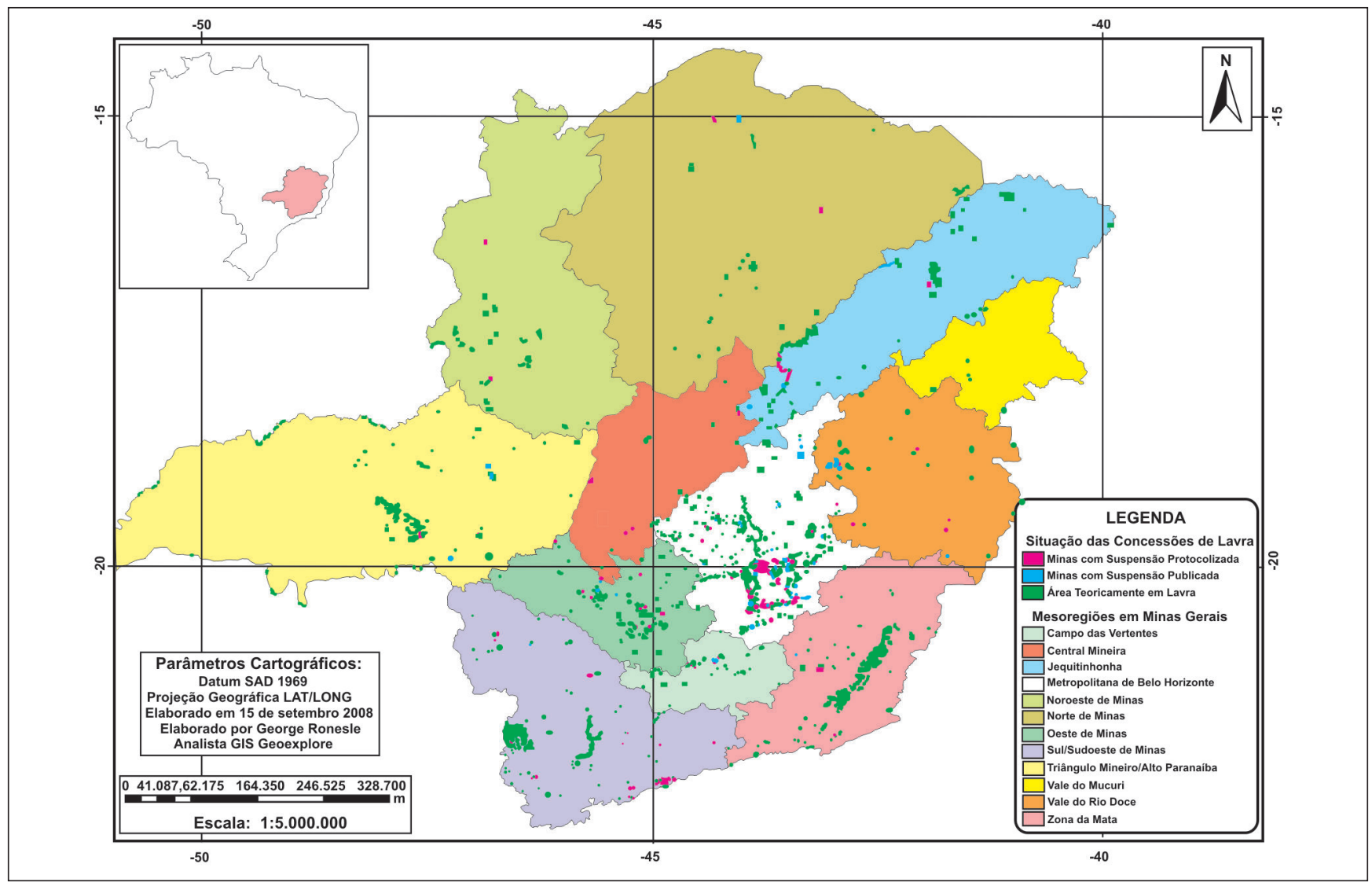

Figura 2 - Mapa georeferenciado de Minas Gerais mostrando a localização das minas e a sua classificação quanto à sua situação operacional. 
As Figuras 4 e 5 apresentam a distribuição das minas com suspensão de lavra protocolizada no DNPM e as minas com suspensão temporária de lavra publicada no DOU, por tipo de substância mineral.

\subsection{Síntese da legislação aplicável}

De acordo com Flores (2007) e Poveda (2007), a legislação aplicável ao fechamento de mina pode ser sumarizada como:

Constituição da República, Artigo 225, Parágrafo $2^{\circ}$ - "Aquele que explorar recursos minerais fica obrigado a recuperar o meio ambiente degradado, de acordo com solução técnica exigida pelo órgão público competente, na forma da lei".

O Decreto $n^{\circ}$ 97.632/89 que dispõe sobre o Plano de Recuperação de Áreas Degradadas, estabelece em seu Art. $1^{\circ}$ - "Os empreendimentos que se destinem à exploração de recursos minerais deverão, quando da apresentação do Estudo de Impacto Ambiental EIA e do Relatório de Impacto Ambiental - RIMA, submeter à aprovação do órgão ambiental competente plano de recuperação de áreas degradada". E no Parágrafo Único - "Para os empreendimentos já existentes, deverá ser apresentado ao órgão ambiental competente, no prazo máximo de 180 (cento e oitenta) dias, a partir da data de publicação deste Decreto, um plano de recuperação da área degradada".

Na Lei 9.605/98 (Lei de Crimes Ambientais), "Art. 55 - Executar pesquisa, lavra ou extração de recursos minerais sem a competente autorização, permissão, concessão ou licença, ou em desacordo com a obtida: Pena - detenção, de seis meses a um ano, e multa. E em seu Parágrafo Único - Nas mesmas penas incorre quem deixa de recuperar a área pesquisada ou explorada, nos termos da autorização, permissão, licença, concessão ou determinação do órgão competente".

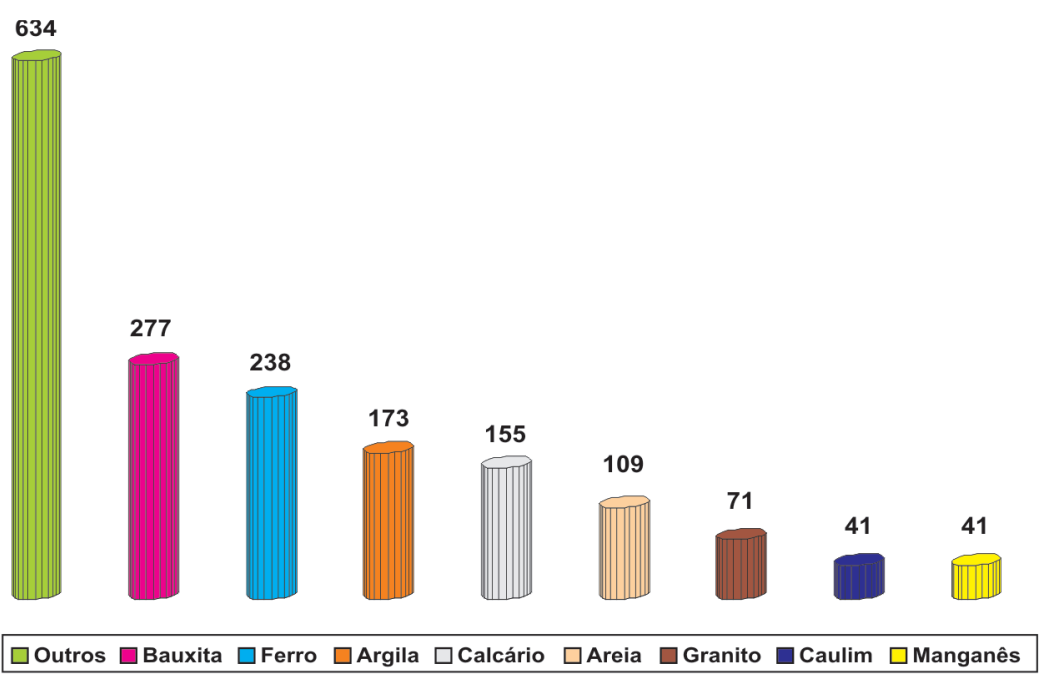

Figura 3 - Mapeamento das concessões de lavra por tipo de substância mineral.

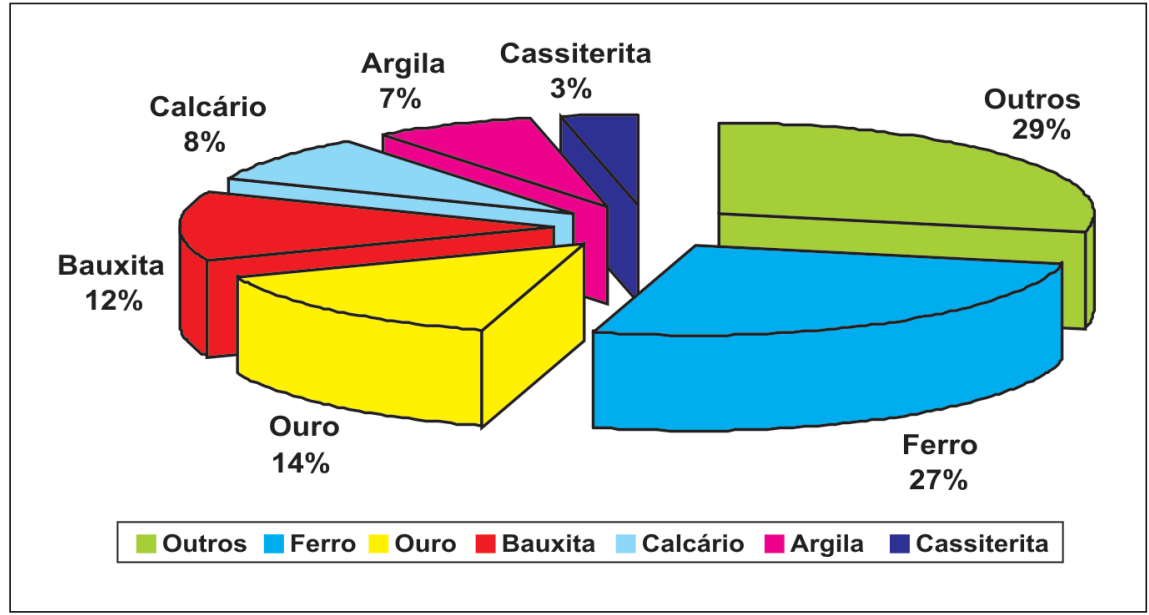

Figura 4 - Distribuição das minas com suspensão temporária de lavra protocolizada no DNPM por substância mineral.

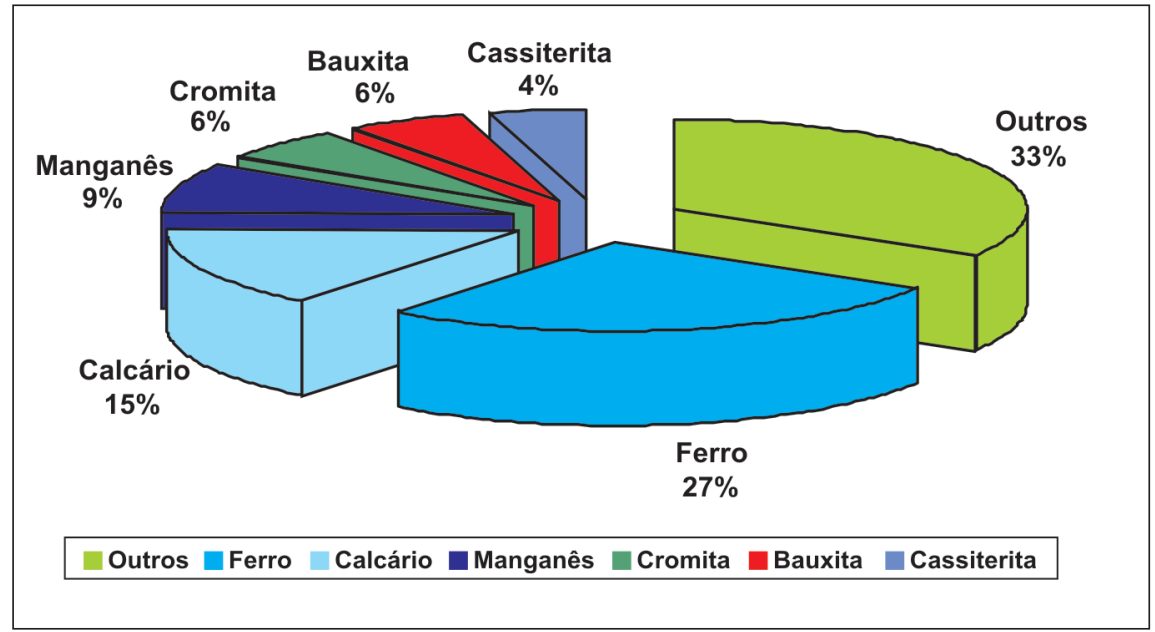

Figura 5 - Distribuição das minas com suspensão temporária de lavra publicada no DOU por substância mineral. 
Nas Normas Reguladoras da Mineração, Portaria/DNPM n ${ }^{\circ}$ 237/2001 a NRM-20 - Suspensão, Fechamento de Mina e Retomada das Operações Mineiras estabelece que para a suspensão das operações mineiras, após comunicação prévia, é obrigatório o pleito ao Ministro de Estado de Minas e Energia em requerimento justificativo caracterizando o período pretendido, devidamente acompanhado de instrumentos comprobatórios, nos quais constem planos de desmobilização, de reabilitação, de monitoramento e manutenção; medidas de segurança; análise de riscos e plano de retomada das operações.

Deliberação Normativa COPAM $N^{\circ} 127 / 2008$ - Estabelece diretrizes e procedimentos para avaliação ambiental da fase de fechamento de mina. Art. $4^{\circ}(\ldots)$ que a partir de 01 de julho de 2009, os processos de revalidação da Licença de Operação de empreendimentos minerários deverão incluir no Relatório de Avaliação do Desempenho Ambiental RADA a descrição de todas as ações implantadas ou em andamento visando à reabilitação da área impactada por atividade minerária, conforme previsto nos estudos ambientais que subsidiaram a análise das Licenças Prévia, de Instalação e de Operação do empreendimento, bem como aqueles indicados pelos órgãos ambientais após as etapas de licenciamento (Minas Gerais, 2008).

\section{Discussão}

$\mathrm{Na}$ análise dos processos no $\mathrm{Ca}$ dastro Mineiro do DNPM pode-se observar que várias minas não tiveram nenhum evento registrado nos últimos anos. Algumas minas não apresentam o Relatório Anual de Lavra (RAL) - instrumento obrigatório para todos os titulares ou arrendatários - há pelo menos 29 anos. A ausência de eventos pressupõe que muitas empresas sequer comunicam a suspensão temporária de lavra ao DNPM, o que demonstra a existência de falhas no gerenciamento dos processos. Pode-se, ainda, estimar que o número de minas com suspensão temporária de la- vra seja superior ao verificado no levantamento das concessões de lavra. Adicionalmente, a análise dos processos possibilita verificar a prática, de algumas empresas, de protocolizar o pedido de suspensão temporária de lavra e, sistematicamente, renová-lo ao longo dos anos. Isso explica a existência de minas com suspensão de longa duração, algumas sem perspectiva de reabertura, e, muito provavelmente, sem nenhuma atividade de manutenção e monitoramento.

Suspensões temporárias de lavra podem possuir relação direta com o mercado. Esse fato é evidente para os minérios de ouro e manganês. No caso do ouro, $44 \%$ das concessões de lavra existentes no Estado estão com suspensão temporária de lavra. A queda acentuada no preço de venda do ouro a partir do ano de 1997 , de US\$ 384,00 para US\$270,00/onça no início do ano 2000, contribuiu para essas suspensões nesse período.

Com relação ao manganês, observou-se que $32 \%$ das concessões de lavra estão com suspensão temporária, também motivada pela questão mercadológica, já que a comercialização apresenta algumas peculiaridades bastante distintas do minério de ferro. O mercado de manganês não trabalha com contratos de fornecimento de longo prazo e o preço é negociado caso a caso. Além disso, o transporte transoceânico é viável somente para minérios de alto teor.

Em relação ao porte das empresas mineradoras, observou-se que as empresas de pequeno porte são responsáveis, respectivamente, por $43 \%$ das suspensões temporárias protocolizadas e por $56 \%$ das suspensões temporárias publicadas. Uma das possíveis causas pode estar ligada à questão comercial, já que as empresas de pequeno porte são mais suscetíveis às variações do mercado, além de enfrentarem forte concorrência das empresas de grande porte, como ocorre, principalmente, no caso do minério de ferro, onde acabam prevalecendo os grandes players.

\section{Conclusões}

As principais razões que conduzem às suspensões temporárias de lavra incluem: a questão comercial (ex. ouro e manganês); fatores logísticos para escoamento da produção; problemas operacionais; acidentes; ações judiciais, empobrecimento dos teores e a existência de reservas remanescentes (Laurence, 2005). Entretanto vale ressaltar a inexistência de informações sobre a situação dessas minas quanto às atividades de reabilitação, monitoramento e manutenção a serem implementadas durante a fase de suspensão temporária. Tais informações não se encontram disponíveis no DNPM e sequer no órgão ambiental, o que nos leva a supor que o passivo ambiental decorrente dessa suspensão seja considerável e que, independentemente das reservas remanescentes e do valor do bem mineral no mercado, pode inviabilizar a reabertura de algumas minas e culminar em processos no Ministério Público para um efetivo fechamento dessas minas.

Embora o fechamento e a suspensão temporária de uma mina estejam contidos na NRM 20, a indústria de mineração necessita de diretrizes para que os mesmos sejam implementados de forma técnica, econômica e socialmente responsáveis sem se incorrer em impactos ambientais e socioeconômicos de longo prazo.

Do ponto de vista ambiental, a DN COPAM 127 torna-se um marco importante para a questão do fechamento de mina. Entretanto a mesma não contempla minas em suspensão temporária de atividade.

\section{Referências bibliográficas}

CAMELO, M. S. M. Fechamento de mina: análise de casos selecionados sob os focos ambiental, econômico e social. Ouro Preto: Departamento de Engenharia Civil, Universidade Federal de Ouro Preto, 2006. 107f. (Dissertação de Mestrado). 
FLORES, J. C. C., LIMA, H. M. Mine closure: legal and socioeconomical issues in Brazil. In: MINE CLOSURE SEMINAR. Santiago, 2007. v. 1, p. 500-510.

LAURENCE, D. Optimisation of the mine closure process. Journal of Cleaner Production, Sydney, Australia, n.14, p. 285-298, 2005.
LIMA, H. M., CUNHA, M. F., BARCELLOS, D. Mine Closure: The State of Art in Minas Gerais State. Santiago: Mine Closure Seminar, 2007. v. 1, p. 400-411.

MINAS GERAIS (Estado). Deliberação Normativa COPAM No 127, de 27 de novembro de 2008. Estabelece diretrizes e procedimentos para avaliação ambiental da fase de fechamento de mina. Diário do Executivo - "Minas Gerais" - 29/11/2008.

POVEDA, E. P. R. A eficácia legal na desativação de empreendimentos minerários. São Paulo: Signus Editora, 2007.238p.

VIANA, M. B. Licenciamento ambiental de minerações em Minas Gerais: novas abordagens de gestão. Brasília: Centro de Desenvolvimento Sustentável, Universidade de Brasília, 2007. 305f. (Dissertação de Mestrado).

Artigo recebido em 02/06/2009 e aprovado em 12/08/2009.

\section{Descubra as muitas informações da:} Geologia, Mineração,
Metalurgia \& Materiais e Engenharia Civil.
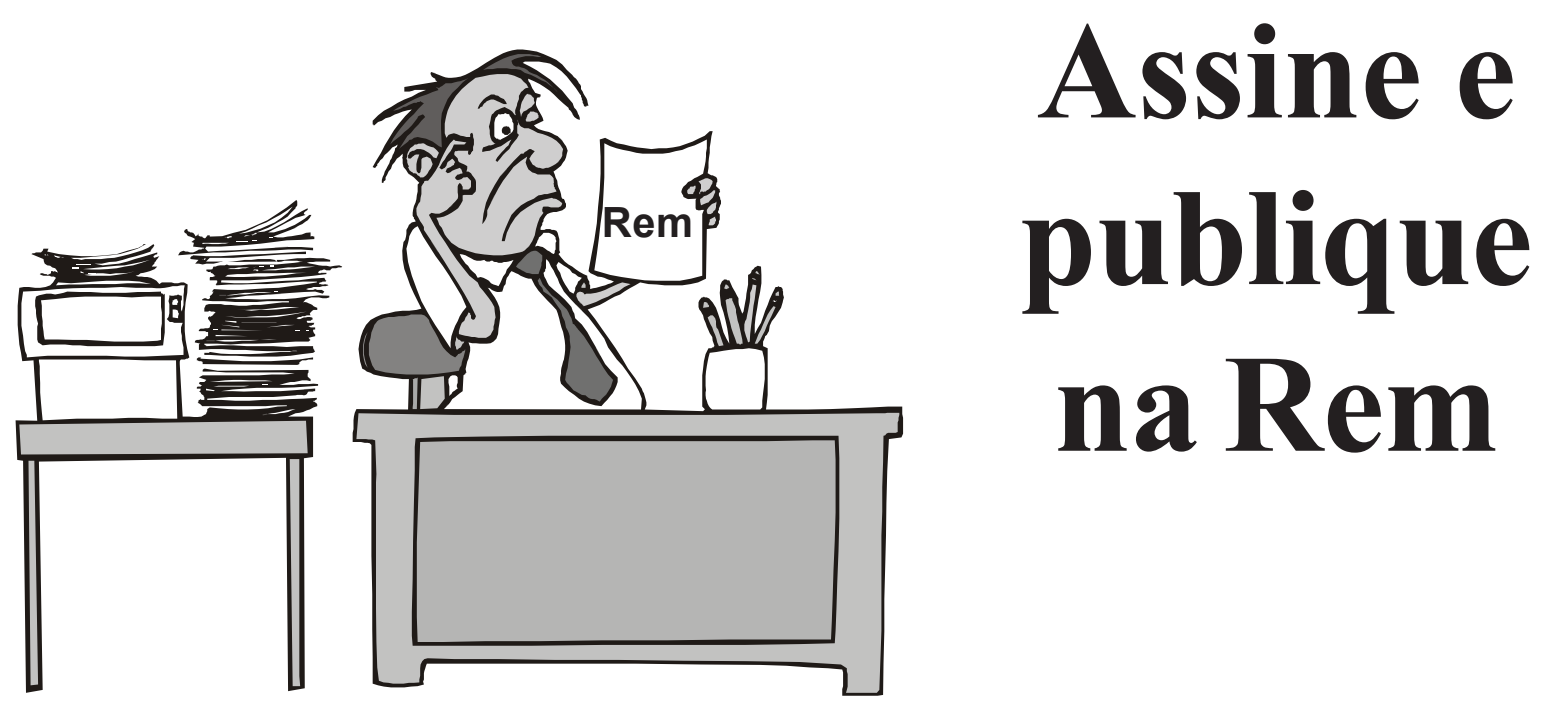

Conheça o nosso site: WWW.rem.com.br 